\title{
Excretion rates and metabolites of oestradiol and progesterone in baboon (Papio cynocephalus cynocephalus) faeces
}

\author{
S. K. Wasser ${ }^{1,2}$, S. L. Monfort ${ }^{2}$, J. Southers ${ }^{3}$ and D. E. Wildt ${ }^{2}$ \\ ${ }^{1}$ Division of Reproductive Endocrinology, Department of Obstetrics and Gynecology, XD-44, University of \\ Washington, Seattle, WA 98105, USA; ${ }^{2}$ Department of Animal Health, National Zoological Park, \\ Conservation and Research Center, 1500 Remount Rd, Front Royal, Virginia 22630, USA; and \\ ${ }^{3}$ Primate Research Unit, National Institutes of Health, Bethesda, MD 20892, USA
}

Two unanaesthetized female yellow baboons (Papio cynocephalus cynocephalus) were infused (i.v.) with $\left[{ }^{3} \mathrm{H}\right]$ oestradiol and two with $\left[{ }^{3} \mathrm{H}\right]$ progesterone, early in the follicular phases of their cycles. One month later, the two females infused with $\left[{ }^{3} \mathrm{H}\right]$ oestradiol were simultaneously infused with $\left[{ }^{14} \mathrm{C}\right]$ progesterone and $\left[{ }^{3} \mathrm{H}\right]$ dehydroepiandrosterone. All urine and faeces were collected for $96 \mathrm{~h}$ after infusion. The proportion of steroid excreted in faeces (versus urine) was $10.0 \%$ for oestradiol and $40 \%$ for progesterone. Peak excretion in urine occurred $4.5 \mathrm{~h}$ after infusion. Peak excretion in faeces occurred an average of $36.4 \mathrm{~h}$ after infusion, with remarkable consistency between steroids. Eighty per cent of faecal oestradiol and progesterone metabolites were excreted as free (rather than conjugated) steroids. Simply boiling $(20 \mathrm{~min}$ ) the dried faecal sample in $90 \%$ ethanol proved to be the most rapid and efficient means of extracting these steroid metabolites. High pressure liquid chromatography and immunoreactivity studies revealed that oestradiol was excreted in faeces as oestradiol $(36 \%)$, oestrone $(44 \%)$ and a conjugated metabolite that co-eluted with oestrone sulfate $(20 \%)$. Progesterone was excreted as eight different free forms, only a minor portion of which was progesterone, and what appeared to be a conjugated metabolite that co-eluted with pregnanediol-glucuronide $(20 \%)$. The free progesterone metabolites were identified by gas-chromatography-mass-spectrometery as epimers of 5-pregnane-3-diol and 5-pregnane3 -ol-one. These data suggest that currently available immunoassays for free oestradiol and oestrone should adequately characterize faecal oestrogen profiles in baboons. However, high variability in crossreactivities of various progesterone antisera to progesterone metabolites in baboons makes antiserum selection a more serious concern in attempts to quantify faecal progestogen dynamics. All available data suggest considerable interspecific variability in faecal steroid metabolite excretion. This makes species-specific characterizations of the type reported here a necessary step for ensuring the accuracy of faecal endocrine monitoring.

\section{Introduction}

Interest in the use of faecal steroid monitoring as an index of endocrine status has grown considerably in recent years for a wide variety of species (Lasley and Kirkpatrick, 1991; Wasser et al., 1991; Schaftenaar et al., 1992). However, successful application of the basic technique requires knowledge of the lag-time between steroid secretion in the blood and excretion in faeces (excretion lag-time), as well as the metabolic forms in which these steroids are excreted. The lag-times are necessary to determine the time between the occurrence of physiological events and their detection in faeces. Knowledge of metabolic forms is critical for maximizing efficiency of the immunoassays used to quantify faecal steroid profiles.
Several differences have been measured in the proportion of steroid hormone excreted in faeces versus urine, both across hormones (progestogens and oestrogens) and within hormone classes across species. For example, reports of faecal oestrogen excretion in primates range from $16 \%$ in ring-tailed lemurs to $93 \%$ in the slow loris (Perez et al., 1988). There are also interspecific differences in excretion lag-time as well as the form of metabolites, including the proportion of free versus conjugated steroids (Perez et al., 1988). As these kinds of data accumulate, a comparative approach may become useful for illuminating the biological bases that underlie these species differences. The present study on yellow baboons hopefully will contribute to this end.

Female baboons were infused with $\left[{ }^{3} \mathrm{H}\right]$ oestradiol and $\left[{ }^{3} \mathrm{H}\right]$ progesterone to determine the proportion of each steroid excreted in faeces compared with urine, their respective excretion lag-times, their metabolic form(s) of excretion in 
faeces and the most efficient means of extracting these metabolites from the faecal sample. We focused upon faecal steroid metabolites because of the novelty and potential field use of the faecal steroid technique compared with that for urine (Goldzieher and Axelrod, 1969; Ishihara et al., 1975; Hodges et al., 1986).

\section{Materials and Methods}

\section{Animals}

The four adult (7-10 years old) female yellow baboons (Papio cynocephalus cynocephalus) used in this study were housed in single animal cages at the Primate Research Unit of the National Institutes of Health, Bethesda, MD. All animals were fed a constant diet containing $5 \%$ fibre, described by Wasser et al. (1993). All infusions took place in the early follicular phase of the menstrual cycle.

\section{Radioligands and infusion}

Tritium-labelled oestradiol- $\left[2,4,6,7 \cdot{ }^{3} \mathrm{H}(\mathrm{N})\right]\left(111.6 \mathrm{Ci} \mathrm{mmol}^{-1}\right)$ and progesterone-[1,2,6,7- $\left.{ }^{3} \mathrm{H}(\mathrm{N})\right]\left(111.1 \mathrm{Ci} \mathrm{mmol}^{-1}\right)$ were obtained fresh from NEN Research Products (Boston, MA). Each infusion was prepared by adding approximately $100 \mu \mathrm{Ci}$ in ethanol $\left(1 \mu \mathrm{Ci} \mu \mathrm{l}^{-1}\right)$ into a $12 \mathrm{ml}$ glass syringe filled with $5 \mathrm{ml}$ sterile saline. Samples then were vortexed for $15 \mathrm{~s}$ and a $20 \mu \mathrm{l}$ aliquot was removed and counted to confirm that the desired concentration was obtained. Syringes were placed in a sonicating glass washer (Metler Electronics, Pasadena, CA) for $30 \mathrm{~s}$ immediately before infusion to remove steroid molecules adhered to the syringe wall. After each infusion, syringes were rinsed repeatedly with Optima Gold scintillation fluid (Packard Instrument $\mathrm{Co}$, Meridan, $\mathrm{CT}$ ) and the radioactivity of the contents measured to determine the steroid concentration infused (amount infused $=$ d.p.m. in syringe before infusion minus d.p.m. remaining in syringe after infusion). All radioactive counting was conducted using a Beckman LS5801 liquid scintillation counter (Beckman Instruments Inc., Fullerton, CA). Two females were each infused i.v. (09:00 h) with $68.5 \pm 5.2 \mu \mathrm{Ci}\left[{ }^{3} \mathrm{H}\right]$ oestradiol (animals $\mathrm{I}$ and 2) and another two (also at 09:00 h) with $64.1 \pm 1.8 \mu \mathrm{Ci}\left[{ }^{3} \mathrm{H}\right]$ progesterone (animals 3 and 4). One month later, the first two females were infused with a combination of $10 \mu \mathrm{Ci}\left[{ }^{14} \mathrm{C}\right.$ progesterone and $100 \mu \mathrm{Ci}$ $\left[{ }^{3} \mathrm{H}\right]$ dehydroepiandrosterone as part of a separate experiment (Wasser et al., 1993). The progesterone patterns described by Wasser et al. (1993) were almost identical to those described for progesterone in the study reported here.

\section{Sample collection and processing}

All urine and faeces were separated at the time of excretion by a $0.64 \mathrm{~cm}$ mesh stainless steel screen placed on top of a stainless steel pan under each animal's cage. Females were checked every hour and all faecal material and urine collected within $1 \mathrm{~h}$ of voiding for $96 \mathrm{~h}$ after infusion. Samples were stored frozen $\left(-20^{\circ} \mathrm{C}\right)$ in individually labelled vials until processing. A $1 \mathrm{ml}$ aliquot of each thawed urine sample was counted in $20 \mathrm{ml}$ Optima Gold scintillation fluid. Thawed faeces were homogenized in ethanol $\left(0.5 \mathrm{ml}\right.$ ethanol $\mathrm{g}^{-1}$ faeces) to liberate the steroids and the amount of radioactivity in $1 \mathrm{~g}$ of the homogenate was determined. To minimize sample quench, each $1 \mathrm{~g}$ faecal sample was subdivided into about ten scintillation vials (each containing $20 \mathrm{ml}$ Optima Gold), until the ' $\mathrm{H}$ ' number for each vial was <120; the d.p.m. per vial were then summed to generate the total counts $g^{-1}$ faecal sample.

\section{Oestrogen and progestogen extractions and radioimmunoassays}

Faecal samples were dried in a centrifugal evaporator (Savant, Farmingdale, NY). Dried samples were extracted and recoveries of the radiolabelled samples determined using the methods described by Wasser et al. (1993). We also evaluated an abbreviated method recently developed in our laboratory (Brown et al., 1993) comparing extraction recoveries and products of the short and long methods. In the short method, $0.2 \mathrm{~g}$ of dried sample was placed in a $50 \mathrm{ml}$ centrifuge tube with $10 \mathrm{ml}$ of $100 \%, 90 \%$ or $80 \%$ ethanol and boiled for $20 \mathrm{~min}$. After centrifugation $(2000 \mathrm{~g}$ for $15 \mathrm{~min}$ at room temperature), the supernatant was decanted into a $16 \mathrm{~mm} \times 125 \mathrm{~mm}$ tube. An additional $5 \mathrm{ml}$ of the same percentage of ethanol was added to the pellet, vortexed ( $1 \mathrm{~min}$ ), centrifuged at $2000 \mathrm{~g}$ for $15 \mathrm{~min}$ at room temperature and the supernatant added to the $16 \mathrm{~mm} \times 125 \mathrm{~mm}$ tube. The combined supernatant was dried and resuspended in exactly $1 \mathrm{ml}$ methanol. Amount of radioactivity in extractants was determined (100 $\mu \mathrm{l}$ in $5 \mathrm{ml}$ scintillation fluid) to determine extraction recoveries of the radiolabelled metabolites using a quench-curve compensation program on a Beckman LS5801 liquid scintillation counter.

Radioimmunoassays for oestrogens were performed using the methods described by Risler et al. (1987). Radioimmunoassays for progestogens were conducted using a monoclonal progesterone antiserum made against 4-P-11-ol-3, 20-dione hemisuccinate:BSA (Grieger et al., 1990). This antiserum crossreacts $100 \%$ with progesterone, as well as with a variety of epimers of 5-pregnane-3-diol and 5-pregnane-3-olone (see Table 1). Both the coefficients of variation for extraction and assay of two separate internal controls (pooled faecal samples containing high concentrations of oestradiol and progesterone, and low concentrations of oestradiol and progesterone, respectively) were $12.0 \%$ for oestradiol and $9.5 \%$ for progesterone (eight extractions and assays each). Intra-assay coefficients of variation were $<5 \%$ for the oestradiol and progesterone assays.

\section{High pressure liquid chromatography of oestrogens and progestogens}

The number and proportions of oestrogen and progestogen metabolites recovered in faeces were determined by reversephase high pressure liquid chromatography (HPLC) (Microsorb C-18 column, Rainin Inc., Woburn, MA). Before HPLC, extracted faecal samples were passed through a C-18 matrix column (Spice Cartridges, Rainin Inc.) and eluted with $5 \mathrm{ml}$ of $80 \%$ methanol as described by Shackleton (1986). Fractions of $1 \mathrm{ml}$ were collected over $80 \mathrm{~min}$ (flow rate, $1 \mathrm{ml} \mathrm{min}^{-1}$ ) for Downloaded from Bioscientifica.com at 04/26/2023 01:41:06AM 
Table 1. Crossreactivities to four different progesterone antisera of progesterone metabolites identified in baboon faeces by gas chromatography-mass spectrometry, after separation into fractions by HPLC (crossreactivities are relative to the binding of progesterone)

\begin{tabular}{|c|c|c|c|c|c|}
\hline \multirow[b]{2}{*}{ Fraction number } & \multirow[b]{2}{*}{ Progesterone metabolite } & \multicolumn{4}{|c|}{ Antisera } \\
\hline & & Monoclonal $^{\mathrm{a}}$ & $\mathrm{DPC}^{\mathrm{b}}$ & $\mathrm{ICN}^{\mathrm{c}}$ & DSL $^{d}$ \\
\hline $30-31$ & $5 \beta$-Pregnane- $3 \alpha, 17 \alpha$-diol, $20 \alpha$-one & 4.8 & $<0.1$ & $<0.1$ & 0.8 \\
\hline $30-31$ & $5 \alpha$-Pregnane- $3 \beta, 20 \alpha$-diol & $<0.1$ & $<0.1$ & $<0.1$ & $<0.1$ \\
\hline $30-41$ & $5 \alpha$-Pregnane- $3 \alpha, 20 \alpha$-diol & 0.2 & $<0.1$ & $<0.1$ & $<0.1$ \\
\hline $33-35$ & $5 \beta$-Pregnane- $3 \alpha, 20 \alpha$-diol & $<0.1$ & $<0.1$ & $<0.1$ & $<0.1$ \\
\hline $38-41$ & $5 \alpha$-Pregnane- $3 \alpha$-ol-20-one & 36.2 & 15.6 & 2.1 & 9.6 \\
\hline $38-41$ & $5 \alpha$-Pregnane-3 $\beta$-ol-20-one & 96.0 & 43.8 & 7.6 & 54.0 \\
\hline $38-48$ & $5 \beta$-Pregnane-3 $\alpha$-ol-20-one & 7.4 & 31.1 & 5.8 & 19.3 \\
\hline
\end{tabular}

aP4 monoclonal antiserum provided courtesy of J. Roser, University of California, Davis.

${ }^{b}$ Coat-a-count progesterone kit from Diagnostic Products Corporation (Los Angeles, CA).

'Double antibody progesterone kit from ICN Biomedical (Costa Mesa, CA).

${ }^{\mathrm{d} D}$ Double antibody progesterone from Diagnostics Systems Laboratory (Webster, TX).

both oestrogens and progestogens. For oestrogen separation, the solvent gradient consisted of $32-45 \%$ acetonitrile $(A C N)$ : water for the first $20 \mathrm{~min}$, increasing to $60 \%$ over the next $40 \mathrm{~min}$, and then to $100 \% \mathrm{ACN}$ over the remaining $20 \mathrm{~min}$. For separation of progestogens, the solvent gradient consisted of $32-50 \%$ ACN:water for $15 \mathrm{~min}$, increasing to $75 \%$ over the next $40 \mathrm{~min}$ and then to $100 \%$ over the remaining 15 min. Elution profiles of standard tritiated oestradiol, oestrone and oestrone sulfate were determined in separate runs using the above oestrogen gradient. Progesterone, 17ahydroxyprogesterone and pregnanediol glucuronide profiles were determined using the above progestogen gradient.

\section{Gas-chromatography-mass-spectrometry of progesterone} metabolites

Thirty samples of extracted progesterone were purified by HPLC using the progestogen gradient described above. Fractions comprising each metabolite peak (see Results) were pooled and $50 \%$ of this pool was analysed using gaschromatography-mass-spectrometry (GC-MS) according to methods described by Shackleton (1986).

GC-MS was carried out on a Hewlett-Packard 5970 mass spectrometer housing a non-polar 15 metre fused-silicon capillary column. After splitless injection of methyloximetrimethylsilyl derivatives of the steroids, the temperature was programmed between $99^{\circ} \mathrm{C}$ and $165^{\circ} \mathrm{C}$ at $3^{\circ} \mathrm{min}^{-1}$. Initially, the samples were analysed by repetitive scanning and steroids were found and identified from their mass spectra. However, the spectra were of poor quality because the steroids were present in low concentration, particularly in comparison with co-eluting faecal contaminants. Confirmation of the presence of the steroids in the pooled samples was achieved by using more sensitive selected-ion-monitoring methods using ions diagnostic for the identified steroids. The identified steroids had retention times essentially identical to corresponding reference steroids.

\section{Results}

An average of $201 \pm 7 \mathrm{~g}$ faeces and $3622 \pm 650 \mathrm{ml}$ urine were collected per animal over the 4 day collection period. An average of $61.5 \pm 0.1 \%$ of each radiolabel was recovered in the urine and faeces combined over that same period. The proportion of infused oestradiol excreted in faeces (versus urine) was $10.0 \%$ for animals 1 and 2 . The proportion of infused progesterone excreted in faeces (versus urine) for all four animals was $40.5 \pm 0.5 \%$. Because urine volume was on average 18 times greater than faecal volume per elimination, the peak steroid concentrations $\mathrm{g}^{-1}$ faeces tended to be twice that of an equivalent mass $(1 \mathrm{ml}$ ) urine (Table 2 ) (except for animal 2). The concentration (d.p.m.) of a given steroid recovered $g^{-1}$ faeces was more similar across individuals than was the concentration $\mathrm{ml}^{-1}$ urine, even after expressing the urinary steroid concentrations $\mathrm{mg}^{-1}$ creatinine (Table 2). Excretion $\mathrm{g}^{-1}$ faeces was remarkably consistent for most steroids, with the mean peak value occurring $36.4 \mathrm{~h}$ after infusion (Figs 1, 2). Steroid excretion in urine was also quite similar across steroids, peaking on average $4.5 \mathrm{~h}$ after infusion (the first urine sample taken after infusion), with a secondary peak occurring about $24 \mathrm{~h}$ after infusion (Figs 3,4). It is noteworthy that the oestradiol peak $\mathrm{ml}^{-1}$ urine for animal 2 was over ten times greater than for animal I (Fig. 3). However, animal I excreted nearly nine times more urine in its peak sample and nearly five times more urine overall compared with animal 2. Animals 3 and 4 were more comparable in both amplitude of their progesterone peaks (Fig. 4) and volumes of urine excreted. Faecal volumes did not vary markedly among animals, nor did the peak concentrations per steroid (Figs 1, 2).

Extraction recoveries of the radiolabelled metabolites from faeces using the long method were $82 \%$ for oestradiol metabolites and $78 \%$ for progesterone metabolites. Thirteen per cent of both oestradiol and progesterone metabolites were lost in the water fraction as conjugates. Extraction recoveries improved with the short method, with no loss in accuracy: recoveries using 100\% ethanol were $98 \%$ and $96 \%$ for oestradiol and progesterone metabolites, respectively; 
Table 2. Amount of tritium (d.p.m.) $\mathrm{g}^{-1}$ and per total mass in the peak faecal sample and $\mathrm{ml}^{-1}$, per total volume and mg creatinine in the peak urine sample for each baboon studied (animals 1-4)

\begin{tabular}{|c|c|c|c|c|c|c|c|c|c|}
\hline \multirow[b]{2}{*}{ Steroid } & \multirow[b]{2}{*}{ Animal } & \multicolumn{3}{|c|}{ Faeces } & \multicolumn{5}{|c|}{ Urine } \\
\hline & & $\begin{array}{l}\text { Radioactivity } \\
\text { (d.p.m. } \mathrm{g}^{-1} \text { ) }\end{array}$ & $\begin{array}{l}\text { Mass } \\
(\mathrm{g})\end{array}$ & $\begin{array}{l}\text { Total } \\
\text { radioactivity } \\
\text { (d.p.m.) }\end{array}$ & $\begin{array}{l}\text { Radioactivity } \\
\text { (d.p.m. } \mathrm{ml}^{-1} \text { ) }\end{array}$ & $\begin{array}{l}\text { Vol } \\
(\mathrm{ml})\end{array}$ & $\begin{array}{c}\text { Total } \\
\text { radioactivity } \\
\text { (d.p.m.) }\end{array}$ & $\begin{array}{l}\text { Creatinine } \\
\left(\mathrm{mg} \mathrm{ml}^{-1}\right)\end{array}$ & $\begin{array}{l}\text { Radioactivity } \\
\text { (d.p.m.) mg } \\
\text { creatinine }\end{array}$ \\
\hline Oestradiol & 1 & 125593 & 6.69 & 840221 & 61855 & 454.0 & 28082234 & 0.35 & 176225 \\
\hline Oestradiol & 2 & 131837 & 63.97 & 8433606 & 651720 & 51.2 & 33368064 & 1.84 & 354388 \\
\hline Progesterone & 3 & 320460 & 3.04 & 1325746 & 199796 & 69.2 & 13825909 & 1.42 & 140701 \\
\hline Progesterone & 4 & 258468 & 16.64 & 4301641 & 140442 & 174.0 & 24436908 & 0.67 & 208371 \\
\hline
\end{tabular}

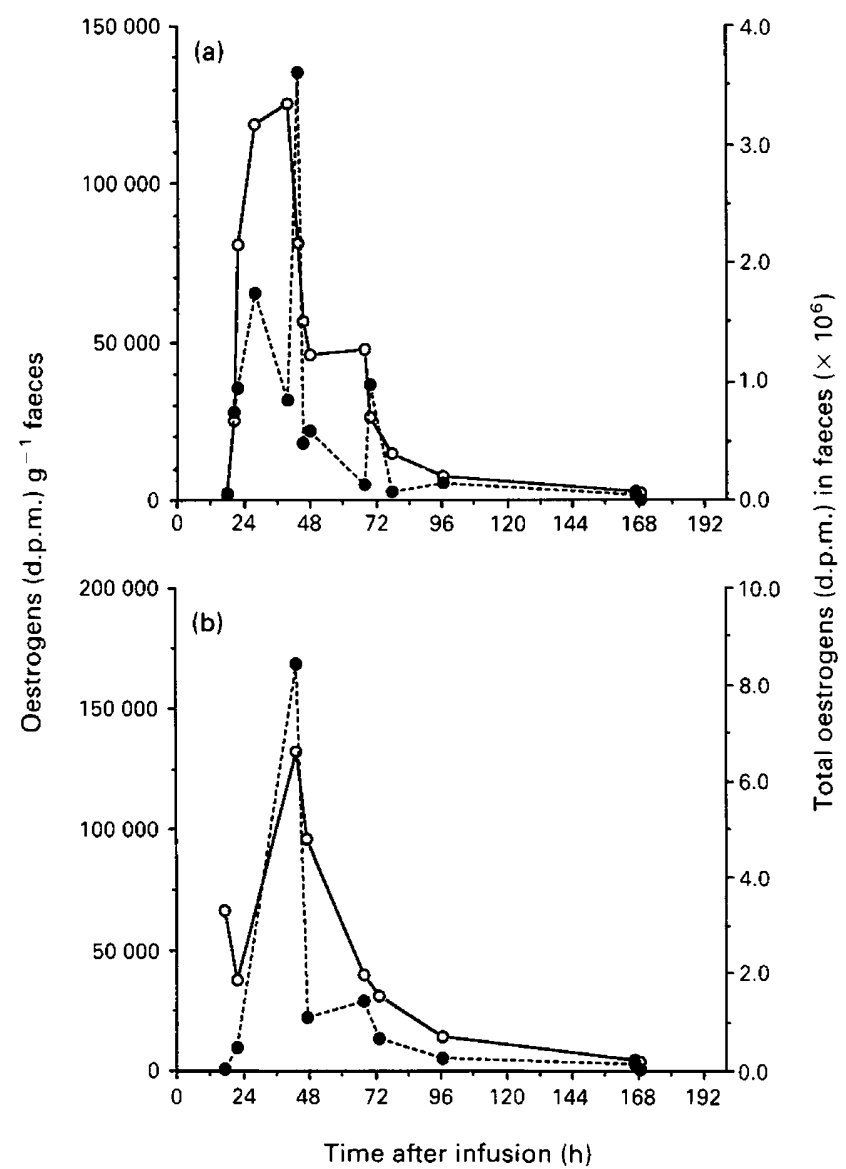

Fig. 1. Faecal excretion rate (in d.p.m.) of infused oestradiol $g^{-1}$ faeces $(0)$ and per total faecal sample $(\bullet)$ over time in baboons for (a) animal $I$ and $(b)$ animal 2.

recoveries using either $90 \%$ or $80 \%$ ethanol were $99 \%$ and $98 \%$ for oestradiol and progesterone metabolites, respectively.

An ether:water (10:1, v:v) extraction was performed on four different samples to establish the total proportion of free versus conjugated oestradiol and progesterone metabolites in the faecal sample, extracted using the long and short methods. Seventeen per cent of each steroid was found to be conjugated in the long method - the $13 \%$ mentioned above, plus an

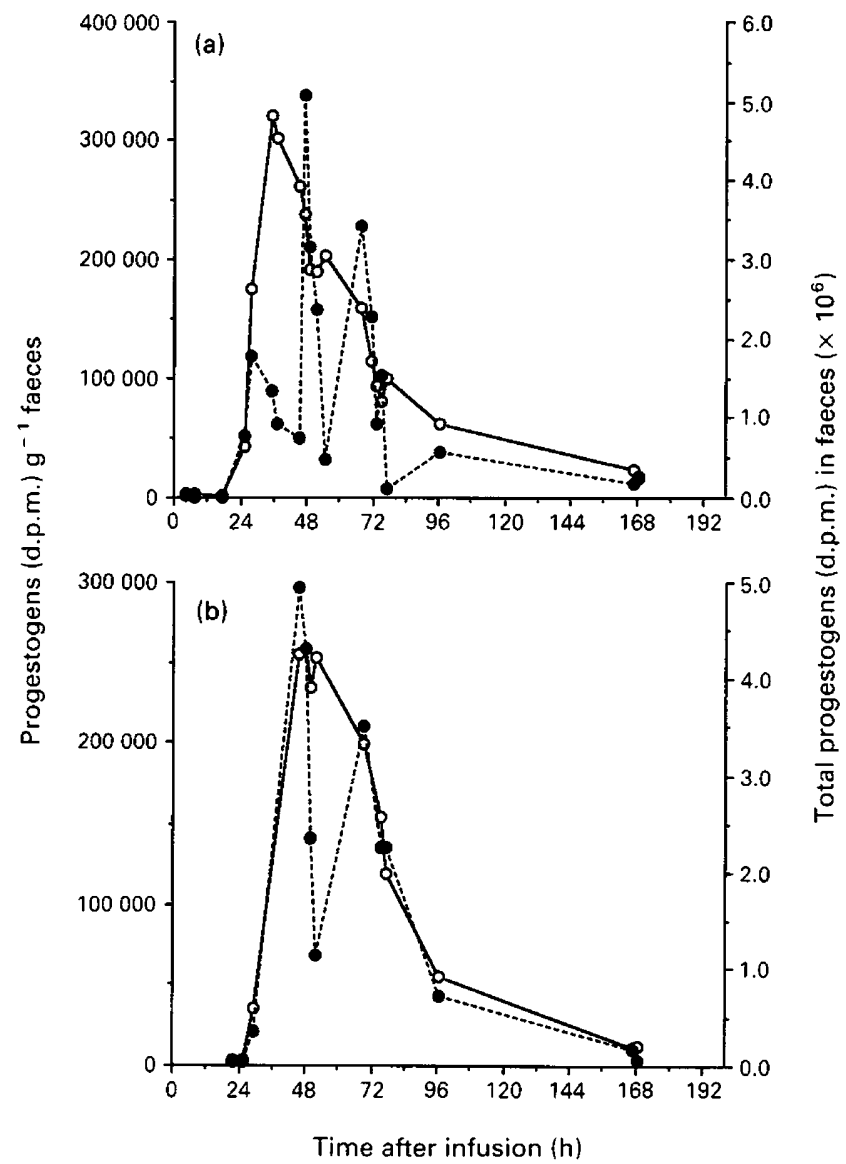

Fig. 2. Faecal excretion rate (in d.p.m.) of infused progesterone $\mathrm{g}^{-1}$ faeces (o) and per total faecal sample (e) over time in baboons for (a) animal 3 and (b) animal 4 .

additional $4 \%$ remaining in the water fraction after the ether:water extraction. The percentage of oestrogen and progestogen conjugates remaining in the water fraction of the ether:water extraction following the short method was similarly $18 \%$ for 80,90 or $100 \%$ ethanol.

To test whether boiling samples in $100 \%$ ethanol hydrolysed conjugate moieties, 30000 c.p.m. each of labelled oestrone sulfate and pregnanediol glucuronide were boiled in ethanol for $20 \mathrm{~min}$ in three separate trials, or placed directly on to faecal 

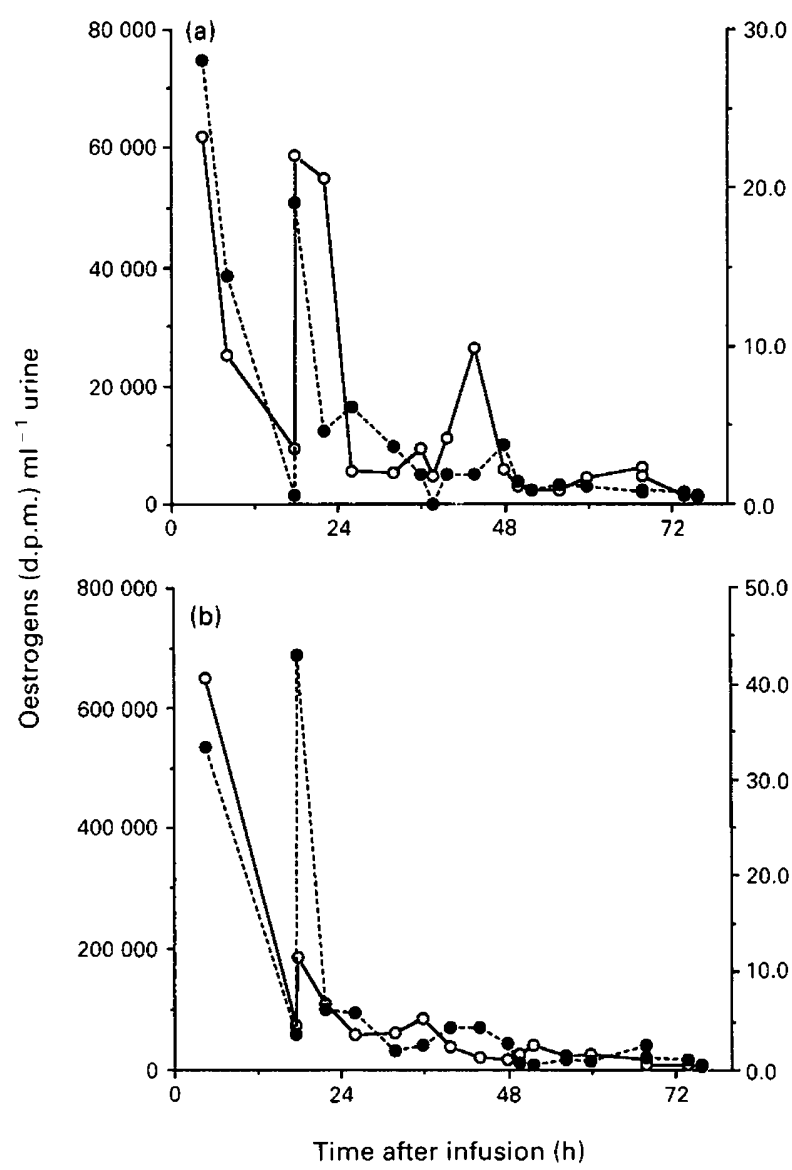

Fig. 3. Urinary excretion rate (in d.p.m.) of infused oestradiol $\mathrm{ml}^{-1}$ urine (o) and per total urine sample ( $)$ over time in baboons for (a) animal 1 and (b) animal 2 .

samples (one steroid per sample) and then boiled in three separate trials. After ether:water extraction, over $90 \%$ of pregnanediol glucuronide and $98 \%$ of oestrone sulfate remained in the water fraction, suggesting that boiling did not significantly hydrolyse the conjugated faecal steroid metabolites in this study.

HPLC of the extracted sample using the short method $(90 \%$ ethanol) revealed that $36 \%$ of the recovered radiolabelled steroid co-eluted with known radiolabelled oestradiol standard, $44 \%$ with oestrone standard, and $20 \%$ as a highly polar metabolite, co-eluting with oestrone sulfate standard in fraction 5 (Fig. 5a). The percentage of conjugates was slightly lower when extracted with $100 \%$ ethanol. HPLC analysis of the dichloromethane:water fraction of the old method further verified that the majority of conjugates remained in the water fraction, whereas the majority of free steroids eluted into the dichloromethane fraction (Fig. 5 b).

To determine whether the ratio of free oestradiol:oestrone remained constant over time and reproductive conditions, two different antibodies (Ab1, S. K. Wasser, Seattle and Ab2, ICN, Costa Mesa, CA) were used to quantify free oestrogen concentrations in 70 faecal samples collected during a 15 month period from an individual free-ranging female baboon across several cycles and a single pregnancy (Wasser et al.,

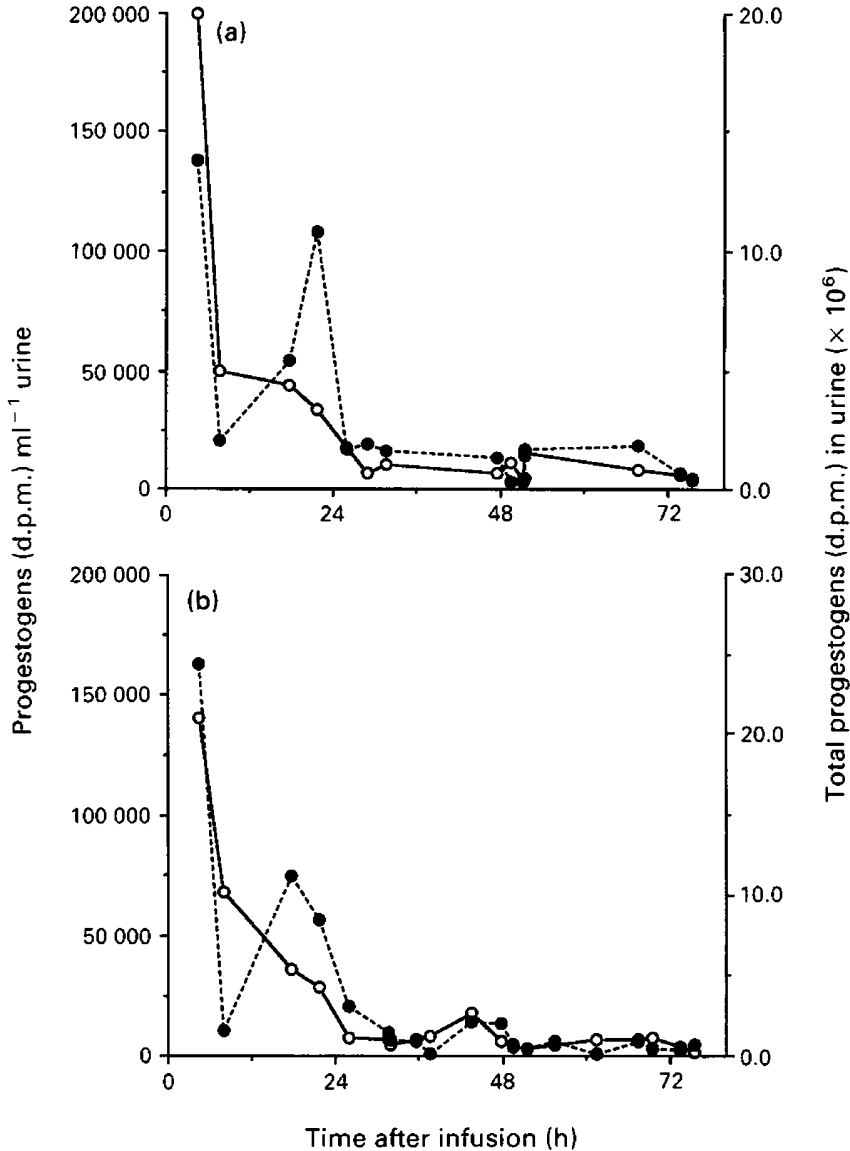

Fig. 4. Urinary excretion rate (in d.p.m.) of infused progesterone $\mathrm{ml}^{-1}$ urine $(0)$ and per total urine sample ( ) over time in baboons for (a) animal 3 and (b) animal 4.

1991). Ab1 crossreacted $100 \%$ with oestradiol and $2 \%$ with oestrone (Risler et al., 1987). Ab2 (from a total oestrogen $\left[{ }^{3} \mathrm{H}\right]$ radioimmunoassay kit, ICN Biomedical, Costa Mesa, CA) crossreacted $100 \%$ with both oestradiol and oestrone. (Neither antibody had affinities for any known oestrogen conjugates.) Thus, if the oestradiol:oestrone metabolite ratio remained constant over time, the $r^{2}$ value of the line regressing results from $\mathrm{Ab} 2$ against $\mathrm{Ab1}$ should be approximately 1.0, with a slope slightly greater than 2.0. In fact, $r^{2}=0.94$ with a slope of 2.29 .

HPLC separation of infused progesterone produced three major and two minor nonpolar peaks and an additional, highly polar peak comprising $<20 \%$ of the total that co-eluted with pregnanediol glucuronide standard in fraction 5 (Fig. 6a). Only a relatively small proportion of progesterone was found in any of these samples.

A nonradioactive faecal sample from a female in the midluteal phase was also separated by HPLC using the progestogen gradient, and fractions were assayed to determine immunoreactivity using a monoclonal progesterone antiserum (see methods) that we have used for monitoring progestogen profiles in our laboratory for a variety of species, including the baboon (Wasser et al., 1993). No immunoreactive progesterone was detected using the monoclonal progesterone antiserum 

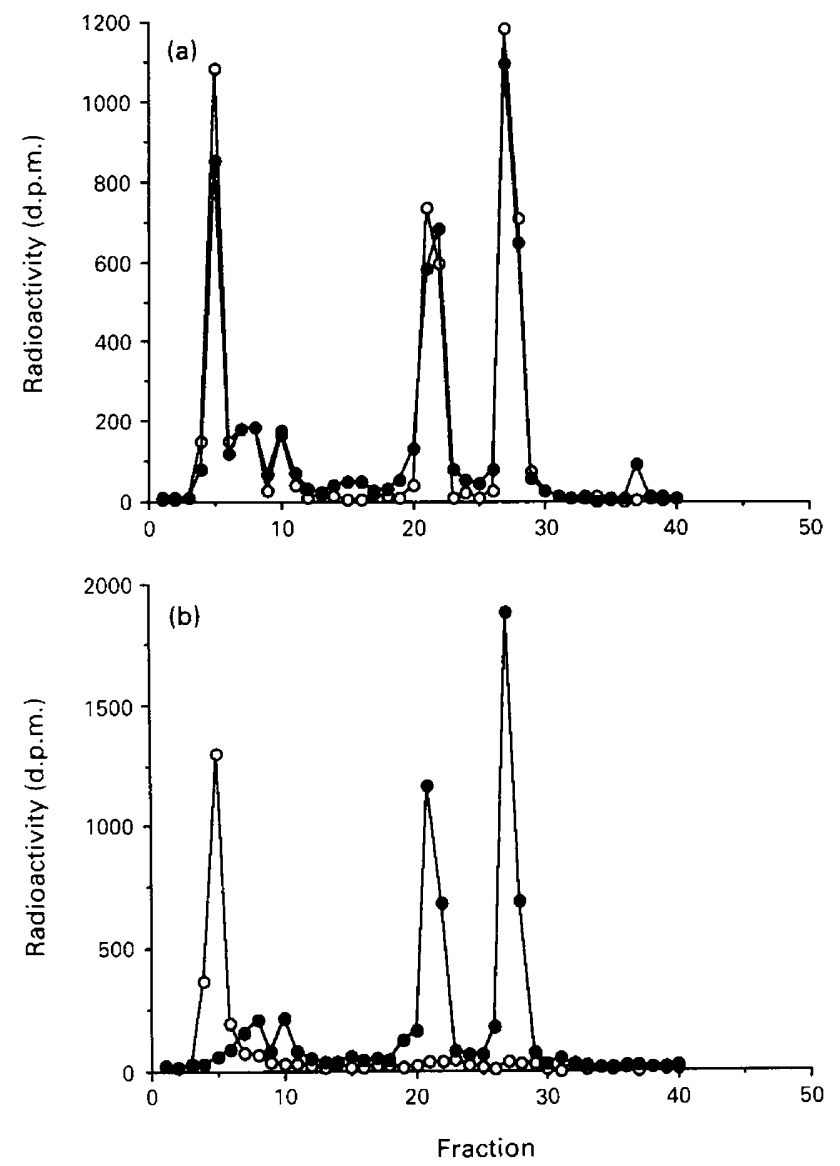

Fig. 5. High pressure liquid chromatography separation of $\left[{ }^{3} \mathrm{H}\right]$ oestradiol metabolites excreted in baboon faeces after extraction by (a) the short method in $90 \%(0)$ or $100 \%$ (•) ethanol, and (b) the long method followed by ether:water separation of free $(\bullet)$ and conjugated metabolites (O), respectively. $\left[{ }^{3} \mathrm{H}\right]$ Oestrone sulfate standard co-eluted with the first peak in fractions $4-6 ;\left[{ }^{3} \mathrm{H}\right]$ oestradiol standard co-eluted with the second peak in fractions $20-23$; and $\left[{ }^{3} \mathrm{H}\right]$ oestrone standard co-eluted with the third peak in fractions $26-29$.

(Fig. 6b). However, substantial immunoreactive peaks were associated with HPLC fractions $38-41$ and $45-48$.

Table $I$ shows the progesterone metabolites in HPLC fractions 30-48 identified by GC/MS, along with their respective crossreactivities to four different progesterone antisera. Taken together, these results suggest that the primary progesterone metabolites that are characterized in our current and previous baboon studies are $5 \alpha$-pregnane-3 $\alpha$-ol-20-one, $5 \beta$-pregnane-3 $\alpha$-ol-20-one and $5 \alpha$-pregnane-3 3 -ol-20-one (see Fig. 6a, b, Table 1).

\section{Discussion}

Studies such as this provide at least four basic types of information regarding faecal steroid analysis technology: (1) the time-course of steroid excretion in faeces relative to the biological event; (2) the efficiency of extraction methods for the particular steroid metabolites being extracted; (3) the predominant metabolic forms of excreted steroids, and hence
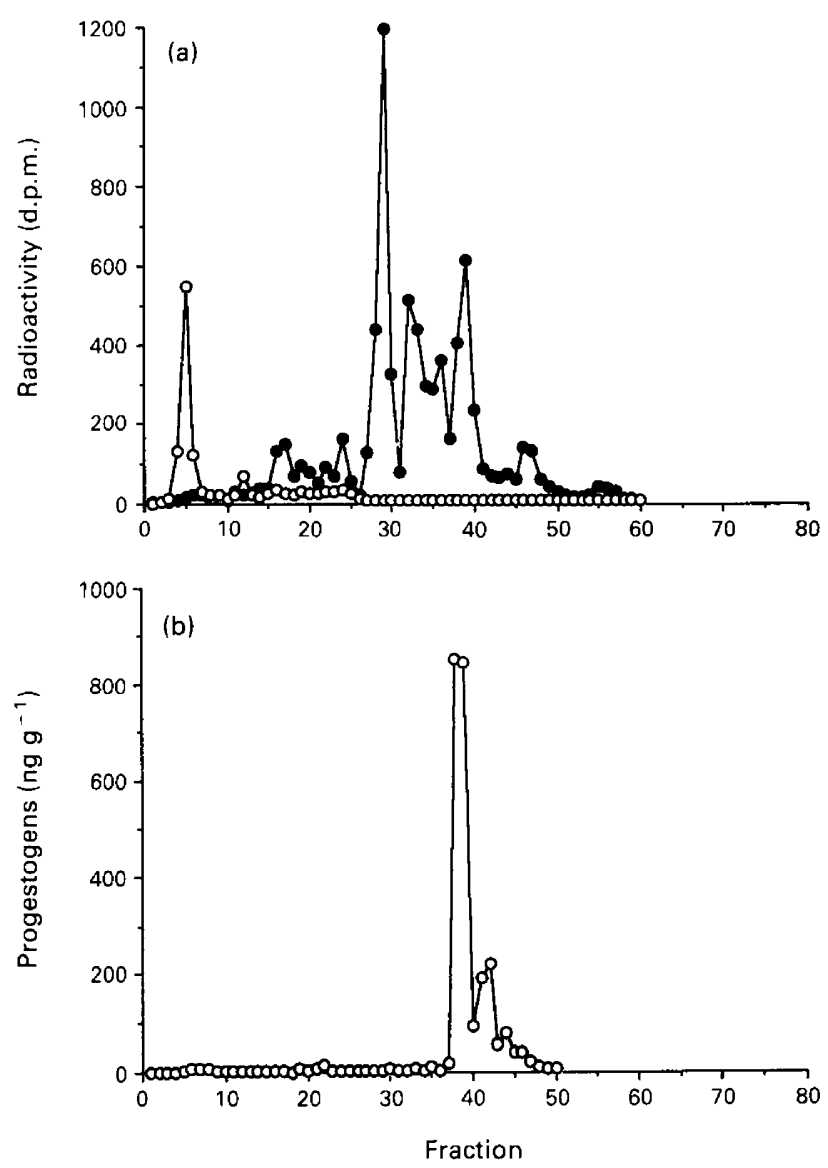

Fig. 6. Fractions showing (a) radioactivity following high pressure liquid chromatography (HPLC) separation of $\left[{ }^{3} \mathrm{H}\right]$ progesterone metabolites excreted in baboon faeces after extraction by the short method in $90 \%$ ethanol, followed by ether:water separation of free ( $\bullet$ and conjugated metabolites ( 0 ), respectively; and (b) immunoreactivity following HPLC separation of an unlabelled, mid-luteal phase faecal sample. Specific progestogen metabolites identified per peak are shown in Table 1. $\left\{{ }^{3} \mathrm{H}\right]$ Progesterone standard eluted in fractions 35-38.

the appropriateness of various antisera for faecal steroid analyses; and (4) improved understanding of the relation between gastrointestinal and renal dynamics and therefore of how these two excretory systems interact to influence steroid excretion within (see for example Wasser et al., 1993) and among species.

Extraction recoveries were highest using our short method, with no loss in accuracy. The abbreviated method eliminated the dichloromethane:water extraction step from the extraction procedure by Wasser et al. (1993); this resulted in a considerable time saving, simultaneously removing virtually all toxic chemicals from our procedure. Three different ethanol concentrations (100, 90 and $80 \%$ ) were compared in the boiling step. Decreasing the percentage of ethanol from 100 to $90 \%$ resulted in only a $1 \%$ improvement in extraction of the oestradiol metabolites and an $18 \%$ improvement in extraction of progesterone metabolites. Further decreasing the ethanol concentration did not improve recoveries. However, increasing the water concentration in $10 \%$ increments may further improve Downloaded from Bioscientifica.com at 04/26/2023 01:41:06AM 
steroid extractions when higher amounts of conjugates are present in faeces. (The cost of increasing the water concentration in this step is an increase in drying time.) This abbreviated extraction procedure is considerably faster and provides $31 \%$ and $17 \%$ higher recoveries for metabolized oestradiol and progesterone, respectively, compared with the abbreviated method described by Shideler et al. (1993).

Ten per cent of oestradiol was excreted in faeces, $73 \%$ of which was unconjugated; $32 \%$ was oestradiol and $41 \%$ was oestrone. In contrast, a higher percentage of progestogens was excreted in baboon faeces $(40 \%)$ and this was metabolized into more total forms compared with the oestrogens. Only a small portion of the progestogens was excreted as progesterone. The $90 \%$ ethanol extraction revealed that a portion of these progesterone metabolites $(20 \%)$ was excreted as conjugates in baboon faeces. At least two of the free progesterone metabolites $(3 \alpha, 20 \alpha$, pregnanediols) were similar to those found as free or conjugated progestogens in baboon urine (Goldzeiher and Axelrod, 1969). However, in contrast to baboon urine, considerable amounts of pregnanelones were also found in baboon faeces. Moreover, no androsterone was detected in our samples despite the fact that this was the predominant progesterone metabolite in baboon urine (Goldzieher and Axelrod, 1969). Compared with progesterone, it appears that the metabolism of oestradiol is highly conserved in baboons and other species (Shackleton, 1974; Ishihara et al., 1975; Adlercreutz and Martin, 1980; Ziegler et al., 1989; Lasley and Kirkpatrick, 1991; Möstl, 1992).

This study also suggests that a combined free oestradiol and oestrone immunoassay is appropriate to quantify faecal oestrogens in the baboon. However, caution must be used in selecting an appropriate progestogen antibody. We compared four antisera, each presumed to be 'highly specific' for progesterone; these comparisons revealed substantial variation in antisera crossreactivities among the faecal progestogen metabolites found in baboons.

Although more of each steroid was excreted in urine than in faeces $(90 \%$ for oestradiol and $60 \%$ for progesterone), the concentration of steroid excreted $\mathrm{g}^{-1}$ excreta ( $1 \mathrm{ml}$ of urine has a mass of $1 \mathrm{~g}$ ) was approximately twice as high in faeces than in urine for all but one animal. For this reason, faecal endocrine analysis may be just as representative of endocrine status as urinary assessments in baboons. In fact, per unit measure, faecal measures may be even more precise than those from urine. Peak concentrations $\mathrm{g}^{-1}$ faeces were quite comparable for a given steroid, despite a 5-10-fold variation in faecal weights. By contrast, a ninefold difference in urine volumes corresponded to a tenfold difference in oestradiol concentration $\mathrm{ml}^{-1}$ in the peak samples of animals $\mathrm{I}$ and 2 . Adjusting the urinary steroid concentrations $\mathrm{mg}^{-1}$ creatinine reduced the interindividual urinary variation per steroid, but this variation still remained substantially higher than that for faeces $\mathrm{g}^{-1}$ (this study and Wasser et al., 1993).

Diet has been shown to affect steroid excretion in faeces; however, assaying hormones per gram dry mass controls for most of the variability here (Wasser et al., 1993). More recent work using the method by Wasser et al. (1993) found no seasonal differences in faecal steroid profiles, collected across the year during over 100 nonconceptive menstrual cycles in wild baboons (S. K. Wasser, unpublished). Diet varies dramati- cally in wild baboons from one season to the next. Thus, the above results further confirm that diet does not significantly affect our quantification of faecal steroids in the wild.

The time-course of excretion was similar for oestrogens and progestogens, each lagging behind secretion in serum by about $36 \mathrm{~h}$ in faeces (see also Wasser $e t$ al., 1993) and approximately $4.5 \mathrm{~h}$ in urine. Longitudinal correlations between serum and faecal progestogens and oestrogens at lag-times of 1-3 days were highest after 2 days (Wasser et al., 1993), corroborating the $36 \mathrm{~h}$ serum faecal lag-time. The above gastrointestinal and renal excretion rates of oestrogens and progestogens were similar to reports for a host of primate species (Perez et al., 1988; Ziegler et al., 1989; Lasley and Kirkpatrick, 1991). While the majority of oestrogens and progestogens were excreted in free rather than conjugated forms, some conjugated forms ( $18 \%$ for oestrogens and progestogens) were found in faeces using an extraction procedure that contained $90 \%$ or less ethanol.

Although steroid excretion lag-time, percentage of steroid excreted in faeces versus urine, faecal steroid concentration, and percentage of free versus conjugated forms were consistent with many other primate species, there were some marked differences. For example, $93 \%$ of oestrogens were excreted in faeces of the slow loris (Perez et al., 1988) compared with 10\% in the baboon. Recent data from our laboratory indicate a lag-time of $<6 \mathrm{~h}$ in African wild dogs (S. L. Monfort and S. K. Wasser, unpublished) and in maned wolves (A. Velloso and S. K. Wasser, unpublished) with the majority of steroids excreted in faeces. Characterizations of faecal steroid content in cyclic Brazilian maned wolves also revealed that faecal progestogen concentrations were 10-100 times higher than those found in baboons ( $\mathrm{S}$. K. Wasser, unpublished). These interspecific differences may be related to a combination of dietary, hepatic, gastrointestinal and renal adaptations, although changes in excretion rates can be induced within an individual by altering any of these functions (Johnstone and Wilson, 1972; Martin et al., 1975; Adlercreutz et al., 1976, 1979; Goldin et al., 1982; Wasser et al., 1993).

These data are also relevant to urinary steroid excretion given the tight linkage between the two excretory systems. Factors that increase faecal excretion rate of oestrogens and progestogens (for example increased dietary fibre or ingestion of ampicillin) can decrease urinary excretion of these steroids significantly; these reductions appear to result from interruption of enterohepatic recirculation, which in turn results from inhibition of intestinal steroid metabolism (Johnstone and Wilson, 1972; Martin et al., 1975; Adlercreutz et al., 1979; Goldin et al., 1982; Wasser et al., 1993). The effect of enterohepatic recirculation on the relation between urinary and faecal steroid excretion was also reflected in the present study by the secondary peak that occurred in urinary excretion of both steroids.

As data on steroid excretion patterns accumulate across species, comparative analyses that couple such data with species-specific information on diet as well as with gastrointestinal and renal dynamics should become possible. These kinds of analyses should prove to be a powerful tool for uncovering some of the critical questions that remain in the study of faecal and urinary steroid excretion. Given the associations between steroid excretion, dietary fibre and various forms of cancer 
(Nair, 1984), such data could also have important biomedical implications.

This research was funded by grants to SKW from the National Institutes of Mental Health (MH45863) and the Smithsonian Institution. Support also was provided by the Scholarly Studies Program, the Women's Committee of the Smithsonian Institution and the Friends of the National Zoo. Study animals, housing, maintenance and animal care were provided by the Primate Research Unit of the National Institutes of Health. The mass spectrometry was carried out by $C$. Shackleton with E. Roitman and the Children's Hospital Oakland Research Institute, who are supported by NIH Grant DK 33400. The authors are grateful for the help of N. Presley, J. Brown, J. Lucas and B. Ferguson for assistance in all phases of this study. They also thank J. Roser, University of California, Davis, for providing the progesterone monoclonal antibody.

\section{References}

Adlercreutz H and Martin F (1980) Biliary excretion and intestinal metabolism of progesterone and estrogens in man Journal of Steroid Biochemistry 13 23I-244

Adlercreutz $H$, Martin F, Pulkkinen $M$, Dencker H, Rimèr U, Sjöberg NO and Tikkanen MJ (1976) Intestinal metabolism of estrogens Journal of Clinical Endocrinology and Metabolism 43 497-505

Adlercreutz H, Martin F, Järvenpää P and Fotsis T (1979) Steroid absorption and enterohepatic recycling Contraception 20 201-223

Brown JL, Wasser SK, Howard JG, Wells S, Lang K, Collins L, Raphael B, Schwartz R, Evans M, Hoyt R, Volk T, Wildt DE and Graham LH (1993) Development and utility of fecal progesterone analysis to assess reproductive status in felids. In Proceedings of the American Association of Zoo Veterinarians pp 273-276. American Association of Zoological Park Veterinarians, Philadelphia

Goldin BR, Adlercreutz H, Gorbach SL, Warram JH, Dwyer JT, Swenson L and Woods MM (1982) Estrogen excretion patterns and plasma levels in vegetarian and omnivorous women New England Journal of Medicine $\mathbf{3 0 7}$ 1542-1547

Goldzieher IW and Axelrod LR (1969) Urinary metabolites of $4^{14} \mathrm{C}$ progesterone in the baboon (Papio spp.) General and Comparative Endocrinology 13 201-205

Grieger DM, Scarborough R, deAvila DM, Johnson HE and Reeves JJ (1990) Active immunization of beef heifers against luteinizing hormone: III. Evaluation of dose and longevity Journal of Animal Science 68 3755-3764

Hodges JK, Tarara R, Hearn JP and Else JG (1986) The detection of ovulation and early pregnancy in the baboon by direct measurement of conjugated steroids in urine American Journal of Primatology 10 329-338
Ishihara M, Osawa Y, Kirdani RY and Sandberg AA (1975) Progesterone metabolism in the baboon Joumal of Steroid Biochemistry 6 1213-1218

Johnstone F and Wilson GR (1972) Fecal excretion of pregnanediol in pregnancy Journal of Endocrinology 52 409-410

Lasley BL and Kirkpatrick JF (1991) Monitoring ovarian function in captive and free-ranging wildlife species by means of urinary and fecal steroids Journal of Zoo and Wildlife Medicine 22 23-31

Martin F, Peltonen J, Laatikainen T, Pulkkinen M and Adlercreutz H (1975) Excretion of progesterone metabolites and estriol in faeces from pregnant women during ampicillin administration Joumal of Steroid Biochemistry 6 1339-1346

Möstl E (1992) Measuring steroids in faeces of mammals to monitor the reproductive states: success and disappointment. In First International Symposium on Faecal Steroid Monitoring in Zoo Animals pP 5-9 Eds W Schaftenaar, RM Buiter and SJ Dieleman. Royal Rotterdam Zoological and Botanical Gardens

Nair PP (1984) Diet, nutrition intake and metabolism in populations at high and low risk for colon cancer. Introduction: correlates of diet, nutrient intake and metabolism in relation to colon cancer American Joumal of Clinical Nutrition 40 880-886

Perez LE, Czekala NM, Weisenseel KA and Lasley BL (1988) Excretion of radiolabeled estradiol metabolites in the slow loris (Nycticebus coucang) American journal of Primatology 16 321-330

Risler L, Wasser SK and Sackett GP (1987) Measurement of excreted steroids in Macaca nemestrina American Journal of Primatology 12 91-100

Schaftenaar W, Buiter RM and Dieleman SJ, eds (1992) First International Symposium on Faecal Steroid Monitoring in Zoo Animals. Royal Rotterdam Zoological and Botanical Gardens

Shackleton CHL (1974) Steroid excretion in the neonatal period: A comparative study of the excretion of steroids by human, ape and rhesus monkey infants Journal of Steroid Biochemistry 5 113-118

Shackleton CHL (1986) Profiling steroid hormone and urinary steroids Journal of Chromatography 379 91-156

Shideler SE, Ortuño AM, Morán FM, Moorman EA and Lasley BL (1993) Simple extraction and enzyme immunoassays for estrogen and progesterone metabolites in the feces of Macaca fascicularis during non-conceptive and conceptive cycles Biology of Reproduction 48 1290 - 1298

Wasser SK, Monfort SL and Wildt DE (1991) Rapid extraction of faecal steroids for measuring reproductive cyclicity and early pregnancy in free-ranging yellow baboons (Papio cynocephalus cynocephalus) Journal of Reproduction and Fertility 92 415-423

Wasser SK, Thomas R, Nair PP, Guidry C, Southers J, Lucas J, Wildt DE and Monfort SL (1993) Effects of dietary fibre on faecal steroid measurements Journal of Reproduction and Fertility $97567-574$

Ziegler TE, Sholl SA, Scheffler G, Haggerty MA and Lasley BL (1989) Excretion of oestrone, estradiol, and progesterone in urine and feces of the fernale cotton-top tamarin (Saguinus oedipus oedipus) American Journal of Primatology 17 185-195 